\title{
DESEMPENHO AGRONÔMICO DO LÍRIO AMARELO CULTIVADO SOB DIFERENTES TAXAS DE APLICAÇÃO DE ESGOTO DOMÉSTICO EM SISTEMAS ALAGADOS CONSTRUÍDOS
}

\author{
Antonio Teixeira de Matos ${ }^{1}$, Renata Cristina Chagas ${ }^{2}$, Aristea Alves de Azevedo ${ }^{3}$, Paola Alfonsa Vieira Lo Monaco ${ }^{4}$, \\ Benatti Rezende Zaparoli ${ }^{5}$
}

\section{RESUMO}

Objetivou-se, com a realização deste trabalho, avaliar o desenvolvimento e comportamento do lírio amarelo (Hemerocallis flava), quando cultivado em sistemas alagados construídos (SACs), submetidos a diferentes taxas de aplicação superficial (TAS) de esgoto doméstico. Os SACs cultivados com lírio amarelo receberam TAS de 44; 98; 230 e $395 \mathrm{~kg} \mathrm{ha}^{-1} \mathrm{~d}^{-1}$ de DBO de esgoto doméstico. O corte da biomassa vegetal foi efetuado ao início e final do experimento ( 7 meses após). Nela, avaliou-se conteúdo de matéria seca e as concentrações de macronutrientes (N, P e K) e Na na parte aérea, sendo os resultados submetidos à análise de variância e as médias dos fatores foram comparadas, utilizando-se o teste Tukey, adotando-se o nível de $10 \%$ de probabilidade. Com base nos resultados obtidos, pode-se concluir que a altura e a produtividade de massa seca da parte aérea das plantas só deve ser avaliada após cerca de 10 meses do plantio. Para cultivo de lírio em SACs, com aplicação de esgoto doméstico, recomendase TAS próxima de $98 \mathrm{~kg} \mathrm{ha}^{-1} \mathrm{~d}^{-1}$ de $\mathrm{DBO}$, tendo em vista que, nessas condições, se obtém a maior produtividade de matéria seca e maior número de flores.

Palavras-chaves: tratamento de esgoto, leitos cultivados alagados, plantas ornamentais.

\section{ABSTRACT \\ AGRONOMIC PERFORMANCE OF YELLOW LILY CULTIVATED OF DIFFERENT ORGANIC LOADING RATES OF DOMESTIC SEWAGE IN CONSTRUCTED WETLAND SYSTEMS}

The aim of this work was to assess the development and behavior of the yellow lily (Hemerocallis flava), when grown in constructed wetland systems (CWs), at different Superficial Application Rates (SAR) of domestic sewage. The CWs received SAR of 44; 98; 230 and $395 \mathrm{~kg} \mathrm{ha}^{-1} \mathrm{~d}^{-1}$ of BOD, cultivated with yellow lily to the domestic sewage treatment. The plant biomass cutting was made at the beginning and at the end of the experiment (after 7 months). The content of dry matter and concentrations of macronutrients (N, P and K) and Na were evaluated, and the results were subjected to analysis of variance and means of treatments were compared using the Tukey test, adopting a level of $10 \%$ probability. Based on the results obtained, it can be concluded that the height and dry matter yield should be assessed after about 10 months of planting. For lily cultivated in CWs with domestic sewage, it is recommended SAR close to $98 \mathrm{~kg} \mathrm{ha}^{-1} \mathrm{~d}^{-1}$ of BOD, because under these conditions are obtained higher dry matter yield and more flowers.

Keywords: wastewater treatment, wetlands, ornamental plants

\section{Recebido para publicação em 13/12/2011. Aprovado em 17/10/2012.}

1 - Engenheiro Agrícola, Professor Associado do Dep. de Engenharia Agrícola da UFV. E-mail: atmatos@ufv.b.

2 - Engenheira Ambiental, Doutoranda em Engenharia Ambiental pela UFES. E-mail: renataeab@hotmail.com.

3 - Biológa, Professora Adjunta do Departamento de Biologia Vegetal, UFV. E-mail: aazevedos@,ufv.br.

4 - Engenheira Agrícola, Professora do IFES Santo - campus Centro Serrano. E-mail: paolalm@ifes.edu.b.

5 - Engenheiro Agrícola e Ambiental, M.S em Engenharia Agrícola - UFV. E-mail: benatti_ufv@yahoo.com.br. 


\section{INTRODUÇÃO}

Um dos problemas mais sérios enfrentados pelo Brasil está relacionado à precariedade do saneamento básico. Diversas infecções são adquiridas pelos seres humanos devido à incorreta disposição de esgotos sanitários em mananciais de água usada para consumo ou recreação.

Com vistas a solucionar este problema, tem-se investido em estudos de diferentes processos de tratamento de águas residuárias, dentro os quais pode-se destacar o sistema alagado construído (SACs) ou "constructed wetlands", por se mostrar uma solução técnica e economicamente viável. Nestes sistemas, utiliza-se meio suporte-plantamicrorganismos para a depuração dos resíduos, sendo caracterizados por serem robustos, de baixo custo e de simples operação e manutenção. Tais aspectos os tornam ideais para aplicação em regiões carentes de saneamento básico, adequandose perfeitamente às condições de países de clima tropical, que possuam áreas disponíveis à sua implantação, como é o caso do Brasil.

Os SACs de escoamento subsuperficial horizontal têm sido comumente utilizados para o tratamento secundário de efluentes domésticos (BRASIL et al., 2007a; 2007b; 2008; ZURITA et al., 2009) de pequenas comunidades, mas podem também ser aplicados no tratamento de águas residuárias industriais (KADLEC \& WALLACE, 2009) e agroindustriais, como as de suinocultura (MATOS et al., 2009; 2010); laticínios (MATOS et al., 2008) e a do processamento dos frutos do cafeeiro (FIA et al., 2010).

Dentre os componentes fundamentais desses sistemas estão as macrófitas aquáticas neles cultivadas, o substrato e o biofilme de bactérias formado no meio suporte, os quais são responsáveis, direta ou indiretamente, pela remoção de poluentes presentes nas águas residuárias. A escolha da espécie vegetal é, juntamente com outras variáveis de dimensionamento, de fundamental importância para o sucesso do tratamento de águas residuárias em SACs. Dentre as funções das macrófitas aquáticas estão incluídas, além da extração de nutrientes contidos na água residuária; a transferência de oxigênio para o substrato; servir de suporte (rizomas e raízes) para o crescimento de biofilme de bactérias, além de melhoria na permeabilidade do substrato e na estética do ambiente (MATOS et al., 2009).

$\mathrm{Na}$ busca dos melhores desempenhos dos SACs para o tratamento de águas residuárias, pesquisadores têm estudado diferentes tipos de culturas nos SACs. Matos et al. (2008), ao utilizarem SACs cultivados com capim tifton 85 no tratamento de águas residuárias de laticínios (ARL), verificaram que o capim tifton 85 se adaptou bem aos SACs, apresentando bom enraizamento, alta produtividade e grande capacidade de remover nutrientes (N, P e K) e sódio da ARL. Fia et al. (2011) ao tratarem água residuária de suinocultura em SACs cultivados com capim tifton-85 (Cynodon spp.) e taboa (Typha latifolia), verificaram que o capim tifton-85 apresentou maior produtividade e capacidade extratora de nutrientes que a taboa.

Recentemente, alguns trabalhos vêm reportando o uso de plantas ornamentais em SACs, como a helicônia (Heliconia psittacorum) (KONNERUP et al., 2009), a biri (Canna generalis) (KONNERUP et al., 2009; ZANELLA, 2008), o copo-deleite (Zantedeschia aethiopica) (BELMONT \& METCALFE, 2003; ZANELLA, 2008; ZURITA et al., 2008; 2009), o papiro (Cyperus papyrus) (ZANELLA, 2008), o mini papiro (Cyperus isocladus) (ZANELLA, 2008), a ave do paraíso ou estrelícia (Strelitzia reginae) (ZURITA et al., 2009), o antúrio (Anthurium andreanum) (ZURITA et al., 2009) e o Agapanto (Agapanthus africanus) (ZURITA et al., 2009) e a Íris pseudacorus L. (WANG et al., 2009).

De acordo com Zanella (2008), o uso dessas plantas vem proporcionando efeito paisagístico do maciço vegetal, a diminuição nos índices de rejeição do sistema pela população e, com a introdução de espécies de interesse comercial, a possibilidade de geração de trabalho e renda para a população circunvizinha. Segundo Belmont e Metcalfe (2003), o cultivo de flores ornamentais em sistema alagados pode fornecer um benefício econômico necessário para incentivar pequenas comunidades em manter um sistema de tratamento de esgoto.

Neste trabalho teve-se como objetivo avaliar o desempenho agronômico do lírio amarelo (Hemerocallis flava), quando cultivados em 
processo de tratamento de esgoto do tipo sistemas alagados construídos, operados com diferentes taxas de carga orgânica.

\section{MATERIAL E MÉTODOS}

O experimento foi conduzido na Área Experimental de Tratamento de Resíduos Urbanos, do Departamento de Engenharia Agrícola, Universidade Federal de Viçosa, em Viçosa - MG, altitude média de $649 \mathrm{~m}$, latitude $20^{\circ} 45^{\prime} 14^{\prime \prime} \mathrm{S}$ e longitude $42^{\circ} 52^{\prime} 53^{\prime \prime} \mathrm{W}$.

$\mathrm{O}$ esgoto doméstico, proveniente do Condomínio Bosque Acamari, foi bombeado para a área experimental, onde recebeu tratamento preliminar (desarenação, caixa de gordura, peneira e tanque de homogeneização). A distribuição do esgoto doméstico nos SACs ocorreu por gravidade, sendo que os afluentes aos SACs 1, 2 e 3 passaram, ainda, por tratamento primário (tanque séptico retangular de alvenaria, com volume útil de 8,7 $\mathrm{m}^{3}$ e tempo de residência hidráulica de 14 horas). Os SACs em escala piloto foram constituídos por quatro reatores de tratamento do esgoto doméstico (SACs) com fundo plano construídos em alvenaria nas dimensões $0,35 \mathrm{~m}$ de altura $\mathrm{x} 1,0 \mathrm{~m}$ de largura x $24 \mathrm{~m}$ de comprimento. Os reatores foram impermeabilizados com lona de PVC $(0,5 \mathrm{~mm}$ de espessura) e preenchidos com brita \# 0 (diâmetro - D60 = 7,0 mm, Coeficiente de Uniformidade D60/D10 = 1,6 e volume de vazios de 48,4\%), constituindo uma camada de $0,30 \mathrm{~m}$ de espessura. A espécie cultivada nos SACs foi a espécie Hemerocallis flava (lírio amarelo). Na saída dos

Após o plantio das mudas de lírio amarelo, os leitos dos SACs foram preenchidos até a altura de $25 \mathrm{~cm}$ com água proveniente do Ribeirão São Bartolomeu, para iniciar a adaptação das plantas ao meio suporte. Quinze dias após do plantio, os SACs foram esgotados, sendo então preenchidos com efluente primário de esgoto doméstico, assim permanecendo por 60 dias, com a finalidade de adaptação das plantas ao novo meio suporte e ocorrer a formação do biofilme. Após esse período de adaptação do sistema, iniciou-se a aplicação diária de esgoto nas taxas pré-definidas, dando início à fase experimental de monitoramento.

Em todos os SACs, utilizou-se o escoamento subsuperficial $(25 \mathrm{~cm}$ de lâmina de esgoto em escoamento em meio suporte de $30 \mathrm{~cm}$ de altura). Os SACs foram, no entanto, submetidos a distintos tempos de detenção hidráulica (TDH) e qualidade do afluente, sendo o SAC 4 alimentado por esgoto bruto (EB) e os SACs 1, 2 e 3 alimentados por efluentes provenientes do tanque séptico (TS), a fim de se obter as taxas de aplicações orgânicas estabelecidas para os tratamentos. As taxas de aplicações superficiais (TAS) foram de 44, 98, 230 e $395 \mathrm{~kg} \mathrm{ha}^{-1} \mathrm{~d}^{-1}$ de DBO, respectivamente, para os SACs 1, 2, 3 e 4 (Quadro 1).

Quadro 1. Características operacionais dos SACs

\begin{tabular}{lcccc}
\hline \multirow{2}{*}{ Variável } & \multicolumn{4}{c}{ SAC } \\
\cline { 2 - 5 } & $\mathbf{1}$ & $\mathbf{2}$ & $\mathbf{3}$ & $\mathbf{4}$ \\
\cline { 2 - 5 } & TS & TS & TS & EB \\
\hline TDH (d) & 3,9 & 2,0 & 1,0 & 0,75 \\
Vazão $\left(\mathrm{m}^{3} \mathrm{~d}^{-1}\right)$ & 0,74 & 1,45 & 2,9 & 3,8 \\
TAS $\left(\mathrm{kg} \mathrm{ha}^{-1} \mathrm{~d}^{-1}\right)$ & 44 & 98 & 230 & 395 \\
\hline
\end{tabular}

Sendo: TS - tanque séptico; EB - efluente bruto; TDH - tempo de detenção hidráulica e TAS - taxas de aplicação superficiais.

As taxas de aplicações dos esgotos foram controladas, diariamente, por meio de válvulas instaladas nas tubulações de condução do esgoto posicionadas à montante dos SACs, sendo as medições, para ajuste das vazões, efetuadas pelo método direto, utilizando-se um recipiente graduado.

Para caracterização química da água residuária aplicada nos SACs, amostras foram coletadas quinzenalmente e encaminhadas ao Laboratório da Qualidade da Água do Departamento de Engenharia Agrícola, para quantificação das concentrações totais de nitrogênio, fósforo, potássio e sódio. As análises foram realizadas em conformidade com recomendações do Standard Methods for the Wastewater Examination (APHA et al., 2005).

Com base nas concentrações médias no afluente e na vazão, foi calculada a carga de nutrientes e sódio aplicadas diariamente, nos SACs e que estão apresentadas no Quadro 2.

Em relação ao cultivo do lírio amarelo nos SACs, alguns cuidados foram necessários devido 
Quadro 2. Carga aplicada de nutrientes e sódio nos diferentes SACs

\begin{tabular}{|c|c|c|c|c|}
\hline$S \wedge C$ & $\mathrm{~N}$ & $\mathrm{P}$ & $\mathrm{K}$ & $\mathrm{Na}$ \\
\hline 1 & 1,60 & 0,21 & 0,41 & 1,87 \\
\hline 2 & 2,98 & 0,49 & 0,78 & 3,48 \\
\hline 3 & 6,44 & 0,98 & 1,62 & 7,35 \\
\hline 4 & 7,57 & 1,23 & 1,83 & 9,00 \\
\hline
\end{tabular}

à manifestação de pragas ao longo do experimento. No primeiro trimestre do experimento, ocorreu ataque de formigas nas plantas cultivadas em todos os SACs, prejudicando, assim, o desenvolvimento das mesmas. Ao longo do tempo de experimentação, as plantas cultivadas nos SACs também tiveram infestações de pragas como a tripes e o pulgão, os quais foram eliminados fazendo-se três aplicações de inseticida Stron. Além disso, as plantas sofreram ataque de fungos causadores da ferrugem, os quais foram controlados com uma aplicação de fungicida Folicur. O corte da biomassa foi efetuado em duas ocasiões diferentes (29/03 e 28/10), o primeiro corte foi realizado após 21 dias do funcionamento dos SACs nas taxas pré-determinadas de esgoto (96 dias após o plantio dos lírios), enquanto que o segundo corte se deu ao final do experimento (309 dias após o plantio). $\mathrm{O}$ corte foi efetuado na altura de $10 \mathrm{~cm}$ das plantas, a partir da superfície do meio suporte.

As amostras foram colocadas em sacos de papel e levadas à estufa, sob temperatura de $65^{\circ} \mathrm{C}$, com circulação de ar, até atingir massa constante (pressecagem). Em seguida, as amostras foram trituradas em moinho e armazenadas para posterior quantificação do conteúdo de matéria seca e realização da análise nutricional $(\mathrm{N}, \mathrm{P}, \mathrm{K}$ e Na). A quantificação de N-total foi feita pelo método semimicro Kjeldhal, a de P-total por espectrofotometria, e K e Na, por fotometria de chama. As análises laboratoriais foram realizadas em conformidade com recomendações de Kiehl (1985), sendo efetuadas nos laboratórios de Solos e Resíduos Sólidos e de Química de Resíduos do Departamento de Engenharia Agrícola da UFV.

$\mathrm{O}$ experimento foi instalado no Delineamento Inteiramente Casualizado, com 4 tratamentos (SAC 1 - TAS de $44 \mathrm{~kg} \mathrm{ha}^{-1} \mathrm{~d}^{-1}$, SAC 2 - TAS de $98 \mathrm{~kg}$ $\mathrm{ha}^{-1} \mathrm{~d}^{-1}$, SAC 3 - TAS de $230 \mathrm{~kg} \mathrm{ha}^{-1} \mathrm{~d}^{-1}$ e SAC 4 TAS de $395 \mathrm{~kg} \mathrm{ha}^{-1} \mathrm{~d}^{-1}$ ), com 7 repetições (parcelas) para cada corte. Essas repetições decorrem do fato de que, em cada SAC, por ocasião do corte, foram obtidas 7 amostras de plantas, coletadas em área de $1 \mathrm{~m}^{2}$, delimitada por quadro demarcador que foi disposto aleatoriamente ao longo dos SACs. As variáveis dependentes foram matéria seca, concentrações de N, P, K e Na na parte aérea das plantas.

Os dados foram submetidos à análise de variância e análise descritiva (altura de plantas). As médias dos fatores qualitativos (SACs) foram comparadas utilizando o teste Tukey, adotando-se o nível de $10 \%$ de probabilidade.

\section{RESULTADOS E DISCUSSÃO}

Em relação ao cultivo, torna-se importante comentar que as plantas dos SACs 1 (TAS de 44 $\mathrm{kg} \mathrm{ha}^{-1} \mathrm{~d}^{-1}$ ) e 3 (TAS de $230 \mathrm{~kg} \mathrm{ha}^{-1} \mathrm{~d}^{-1}$ ) foram as mais afetadas por pragas, sendo os primeiros doze metros do SAC 3 e os últimos seis metros do SAC 1 as porções mais intensamente afetadas pelas pragas. No SAC 3, ao contrário do que ocorreu no SAC 4 (TAS de $395 \mathrm{~kg} \mathrm{ha}^{-1} \mathrm{~d}^{-1}$ ), houve rebrota das plantas, evidenciando um comportamento importante do Hemerocallis flava, que é o de se propagar vegetativamente. Nos SACs 1 e 3 , as densidades de cultivo foram de 5,0 plantas $\mathrm{m}^{-2}$, ou seja, abaixo dos 5,6 plantas $\mathrm{m}^{-2}$ que haviam sido plantadas no início do experimento, enquanto nos SACs 2 e 4 as densidades foram de 6,6 e 8,5 plantas $\mathrm{m}^{-2}$, respectivamente. No SAC 4, que recebeu maior taxa de aplicação orgânica, as plantas apresentaram maior perfilhamento em relação aos outros SACs.

$O$ fato dos últimos 6 metros do SAC 1 não ter se recuperado, tal como ocorreu no SAC 3, deve-se, provavelmente, à menor disponibilidade de nutrientes nesse meio, quando comparado ao apresentado no SAC 3, dificultando, assim, a adequada nutrição das plantas, impossibilitando, 
com isso, a sua rebrota. Confirma-se tal fato quando se observa que a concentração de nitrogênio no efluente do SAC 1 (24,0 $\left.\mathrm{mg} \mathrm{L}^{-1}\right)$, estatisticamente inferior ao obtido no SAC 3 (37,2 $\left.\mathrm{mg} \mathrm{L}^{-1}\right)$, decorrente da menor taxa aplicada no primeiro. Quanto ao florescimento, o SAC 2 (TAS de $98 \mathrm{~kg}$ $\mathrm{ha}^{-1} \mathrm{~d}^{-1}$ ) se destacou dentre todos, apresentando um total de 22 plantas que floresceram. Os SACs 1, 3 e 4 apresentaram, respectivamente, 17, 5 e 14 plantas que produziram flores.

$\mathrm{O}$ número de flores obtido no SAC 2 foi menor que o obtido em trabalho de Zurita et al. (2009), que foi de 60 flores de copo-de-leite Zantedeschia aethiopica), cultivados em SACs de escoamento subsuperficial horizontal $(3,6 \times 0,9 \times 0,3 \mathrm{~m})$, no tratamento de esgoto doméstico. No entanto, ao submeterem o esgoto doméstico em SACs de escoamento vertical $(1,8 \times 1,8 \times 0,7)$, cultivados com a mesma espécie, observaram o florescimento de apenas 10 flores. A elevada produção de flores no SAC de escoamento horizontal foi atribuída ao fato desta espécie ser adaptada a mecanismos em condições de encharcamento.

Em todos os SACs, constatou-se tendência de maior florescimento nos últimos metros dos leitos. Isso pode estar associado à maior disponibilidade de formas minerais de $\mathrm{N}$ e $\mathrm{P}$ e aumento no potencial redox do meio, tal como observado por Freitas (2006) ao tratar águas residuárias da suinocultura em SACs. Suspeita-se que o amarelecimento observado nas folhas de plantas cultivadas na parte final dos SACs esteja associado à intoxicação com íons tóxicos (notadamente sódio e cloretos), que apresentam aumento relativo nas suas concentrações ao longo dos SACs.

Todas as plantas, no início do experimento
(26/12/2006), possuíam altura média de $10 \mathrm{~cm}$. Entretanto, em janeiro/2007, antes mesmo de ser dado o início da aplicação da água residuária doméstica nos SACs, já se observava pequena variação no desenvolvimento das plantas. Em outubro/2007, observou-se que as plantas do SAC 2 apresentaram melhor desempenho agronômico, apresentando maiores alturas ao longo do SAC, quando comparadas às plantas cultivadas nos SACs 1, 2 e 4 (Figura 1), embora isso só possa ser afirmado com base numa análise descritiva. Acredita-se que a TAS do SAC $2\left(98 \mathrm{~kg} \mathrm{ha}^{-1} \mathrm{~d}^{-1}\right)$ tenha proporcionado o aporte de nutrientes em concentrações mais próximas de um ideal que no caso dos outros SACs e a quantidade crescente de sódio, aplicada via água residuária, pode ser uma das razões para isso.

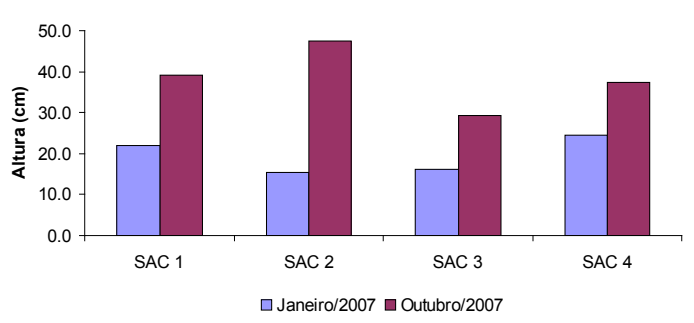

Figura 1. Altura do Hemerocallis flava cultivada nos SACs, em janeiro e outubro de 2007.

As médias de produtividade de massa seca e de concentração de nutrientes e sódio na parte aérea das plantas de lírio amarelo estão apresentadas no Quadro 3.

Apenas a produtividade de massa seca da parte aérea das plantas obtida no segundo corte esteve

Quadro 3. Valores médios de produtividade de massa seca (MS) e das concentrações de nutrientes na parte aérea do material vegetal coletado em dois cortes, em função da TAS.

\begin{tabular}{|c|c|c|c|c|c|c|c|c|c|c|}
\hline \multirow{3}{*}{ SAC } & \multirow{2}{*}{\multicolumn{2}{|c|}{$\begin{array}{c}\text { MS } \\
\mathrm{kg} \mathrm{ha}^{-1}\end{array}$}} & \multirow{2}{*}{\multicolumn{2}{|c|}{$\mathrm{N}$}} & \multicolumn{2}{|c|}{$\mathrm{P}$} & \multicolumn{2}{|c|}{$\mathrm{K}$} & \multirow{2}{*}{\multicolumn{2}{|c|}{$\mathrm{Na}$}} \\
\hline & & & & & -------- & --- dag & -1 ------- & & & \\
\hline & $\begin{array}{c}1^{\mathrm{o}} . \\
\text { corte }\end{array}$ & $\begin{array}{c}2^{\circ} . \\
\text { corte }\end{array}$ & $\begin{array}{c}1^{\circ} . \\
\text { corte }\end{array}$ & $\begin{array}{c}2^{\circ} . \\
\text { corte }\end{array}$ & $\begin{array}{c}1^{\mathrm{o}} . \\
\text { corte }\end{array}$ & $\begin{array}{c}2^{\circ} . \\
\text { corte }\end{array}$ & $\begin{array}{c}1^{\mathrm{o}} . \\
\text { corte }\end{array}$ & $\begin{array}{c}2^{\circ} . \\
\text { corte }\end{array}$ & $\begin{array}{c}2^{\circ} . \\
\text { corte }\end{array}$ & $\begin{array}{c}2^{\circ} . \\
\text { corte }\end{array}$ \\
\hline 1 & $11,24 \mathrm{a}$ & $53,18 b$ & $2,41^{\mathrm{a}}$ & $2,04 \mathrm{a}$ & $0,27 \mathrm{a}$ & $0,21 \mathrm{a}$ & $0,13 \mathrm{ab}$ & $0,16 \mathrm{a}$ & $0,43 \mathrm{a}$ & $0,38 \mathrm{a}$ \\
\hline 2 & $8,19 \mathrm{a}$ & $151,70 \mathrm{a}$ & $2,64^{\mathrm{a}}$ & $1,73 \mathrm{a}$ & $0,27 \mathrm{a}$ & $0,21 \mathrm{a}$ & $0,12 \mathrm{ab}$ & $0,15 \mathrm{a}$ & $0,43 a$ & $0,62 \mathrm{a}$ \\
\hline 3 & $7,41 \mathrm{a}$ & $20,84 b$ & $2,55^{\mathrm{a}}$ & $1,71 \mathrm{a}$ & $0,22 b$ & $0,19 a$ & $0,10 \mathrm{~b}$ & $0,11 \mathrm{a}$ & $0,56 \mathrm{a}$ & $0,48 \mathrm{a}$ \\
\hline 4 & $7,58 \mathrm{a}$ & $52,89 b$ & $2,63^{\mathrm{a}}$ & $1,83 \mathrm{a}$ & $0,28 \mathrm{a}$ & $0,20 \mathrm{a}$ & $0,15 \mathrm{a}$ & $0,13 a$ & $0,38 \mathrm{a}$ & $0,33 a$ \\
\hline
\end{tabular}

Médias seguidas de pelo menos uma mesma letra na coluna não diferem, em nível de $10 \%$ de probabilidade, pelo teste de Tukey. 
diretamente correlacionada à altura média (Figura 1). Isso demonstra que, caso se queira avaliar o desempenho agronômico das plantas em SACs, torna-se essencial que se dê um tempo para a adaptação das plantas ao meio de cultivo, para se não correr riscos de efetuar avaliações incorretas.

Analisando-se o material vegetal obtido no corte efetuado no dia 29/03 ( $1^{\circ}$ corte), ou seja, 96 dias após o plantio do lírio, verifica-se produtividade de massa seca semelhante nos SACs, entretanto, aos 309 dias (corte efetuado em 28/10), a maior produtividade de massa seca foi obtida no SAC 2, submetido à TAS de $98 \mathrm{~kg} \mathrm{ha}^{-1} \mathrm{~d}^{-1}$, tendo sido alcançado o valor de $151,7 \mathrm{~kg} \mathrm{ha}^{-1}$. Suspeita-se que o melhor desempenho das plantas cultivadas no SAC 2 deva-se a fatores nutricionais, ou seja, disponibilidade suficiente de nutrientes sem que tenha sido atingido níveis tóxicos. Tunçsiper et al. (2004) verificaram que altas concentrações de nutrientes na água residuária podem causar danos à vegetação de macrófitas cultivadas em SACs. Hussar (2001) observou a morte de plantas de taboa (Typha latifolia), o que correlacionou à alta concentração de nutrientes na água residuária da suinocultura. Matos et al. (2008) verificaram tendência de decréscimo na produtividade de matéria seca de capim tifton, cultivado em SACs para tratamento de água residuária de laticínios, quando os valores de TAS superaram de $500 \mathrm{~kg}$ $\mathrm{ha}^{-1} \mathrm{~d}^{-1}$ de DBO.

De acordo com os dados apresentados no Quadro 3, pode-se verificar, também, que a produtividade da matéria seca do lírio amarelo aumentou com o tempo, tal como verificado por Fia et al. (2011), quando cultivaram capim tifton e por Matos et al. (2010), quando cultivaram alternantera (Alternanthera philoxeroides (Mart.) Griseb) em SACs utilizados no tratamento de água residuária da suinocultura. Acredita-se que a melhor adaptação das plantas às condições de cultivo possa ser a principal razão para o ocorrido.

Reconhecidamente a produtividade de massa seca de plantas ornamentais é menor que a de forrageiras cultivadas em SACs utilizados no tratamento de águas residuárias. Só para exemplificar, a maior produtividade de massa seca na parte aérea do lírio amarelo obtida no SAC $2\left(151,7 \mathrm{~kg} \mathrm{ha}^{-1}\right)$ é muito inferior à obtida por Fia etal. (2011), os quais aplicaram taxa de carga orgânica de $163 \mathrm{~kg} \mathrm{ha}^{-1} \mathrm{~d}^{-1}$ de DBO em SACs cultivados com capim tifton-85, TAS um pouco superior à aplicada no SAC 2, durante 4 meses no tratamento de água residuária da suinocultura, condição que proporcionou produtividade média de matéria seca de $5,13 \mathrm{tha}^{-1}$.

Torna-se importante comentar que, embora nos 6 últimos metros de comprimento do SAC 1 (TAS de $44 \mathrm{~kg} \mathrm{ha}^{-1} \mathrm{~d}^{-1}$ ) praticamente não existir nenhuma planta, ainda assim foi obtida produtividade média de matéria seca semelhante à obtida no SAC 4 (TAS de $395 \mathrm{~kg} \mathrm{ha}^{-1} \mathrm{~d}^{-1}$ ), que continha plantas distribuída em todo o SAC, sugerindo que as plantas cultivadas no SAC 1 apresentaram maior desenvolvimento na referida faixa do SAC. As plantas cultivadas nos SACs 1 e 3 (TAS de $230 \mathrm{~kg} \mathrm{ha}^{-1} \mathrm{~d}^{-1}$ ) sofreram muito com o ataque de pragas, embora tenha havido rebrota de algumas, no SAC 3. As plantas cultivadas nestes SACs não apresentaram bom desenvolvimento foliar obtendo-se, portanto, a menor média de produtividade de massa seca em relação às obtidas nos outros SACs.

Ao analisar as Figuras 2 e 3 que contêm as concentrações de nitrogênio na parte aérea das plantas de lírio amarelo, respectivamente, em amostras do primeiro e segundo cortes, coletadas ao longo do comprimento dos SACs, verifica-se que as folhagens das plantas no início do experimento apresentaram maiores teores de nitrogênio em relação às do final. Esta diferença provavelmente é devida ao fato de na primeira coleta as plantas estarem em fase de crescimento, ao passo que na segunda coleta as plantas já se apresentavam na fase adulta.

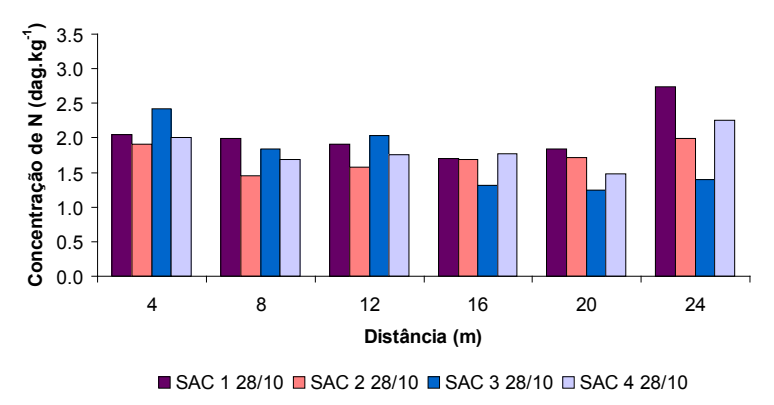

Figura 2. Concentração de $\mathrm{N}$ na parte aérea das plantas de lírio amarelo coletadas no primeiro corte. 


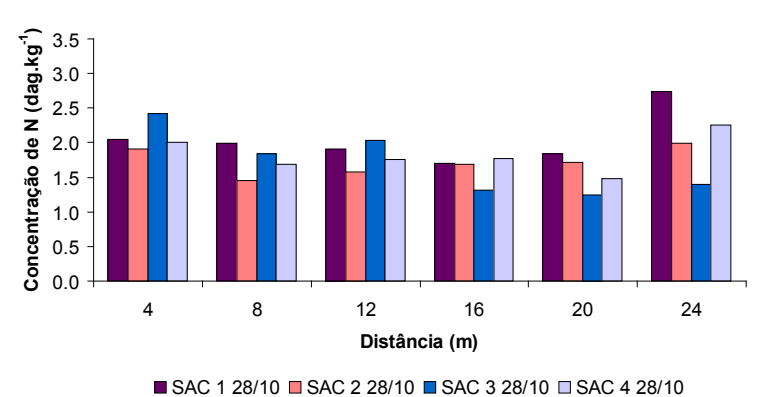

Figura 3. Concentração de $\mathrm{N}$ na parte aérea das plantas de lírio amarelo coletadas no segundo corte.

A TAS não influenciou a concentração de nitrogênio na parte aérea das plantas de lírio amarelo (Quadro 3), em ambos os cortes, contrariando os resultados encontrados por Matos et al. (2008) e Fia et al. (2011), os quais observaram tendência de aumento nas concentrações de nitrogênio na parte aérea do capim tifton, com o aumento da taxa de carregamento orgânico em SACs no tratamento de água residuária de laticínios e suinocultura, respectivamente. A concentração de nitrogênio foi maior em plantas mais jovens, o que foi evidenciado no material coletado no primeiro corte do que em plantas mais velhas, cujo material foi coletado no segundo corte. Observa-se que, de maneira diferente em relação à produtividade de massa seca, o lírio amarelo apresentou comportamento semelhante em relação a forrageiras, quanto à capacidade de acumular nitrogênio na parte aérea, sugerindo que plantas ornamentais podem ser, em alguns casos, tão ou até mais eficientes que as forrageiras na extração de nitrogênio de águas residuárias.

As concentrações médias de nitrogênio nas plantas foram superiores às encontradas por Brasil et al. (2007a) que, ao aplicarem diferentes taxas médias de carregamento orgânico volumétrico (116 a $210 \mathrm{~g} \mathrm{~m}^{-3} \mathrm{~d}^{-1}$ ) em SACs cultivados com taboa, no tratamento de esgoto doméstico, obtiveram concentrações de $1,50 \mathrm{dag}^{-1} \mathrm{~g}^{-1}$; semelhantes às obtidas por Matos et al. (2009) que, ao tratarem efluentes da suinocultura cultivados com taboa, obtiveram 2,13 dag $\mathrm{kg}^{-1}$ deste nutriente e por Fia et al. (2010), que ao aplicarem taxas crescentes de carregamento orgânico (653 a $1.531 \mathrm{~kg} \mathrm{ha}^{-1} \mathrm{~d}^{-1}$ de DQO) de águas residuárias do processamento dos frutos do cafeeiro obtiveram concentrações de
2,13 a 2,42 e de 1,85 a 3,35 dag kg-1 de nitrogênio respectivamente na parte aérea de plantas de azevém e aveia cultivadas em SACs. Matos et al. (2008) obtiveram concentrações de 2,9 a 4,0 dag $\mathrm{kg}^{-1}$ de nitrogênio na parte aérea do capim tifton quando cultivados em SACs, que receberam taxas crescentes (66 a $\left.570 \mathrm{~kg} \mathrm{ha}^{-1} \mathrm{~d}^{-1}\right)$ de águas residuárias de laticínios. Fia et al. (2011), ao aplicarem taxas crescentes de carregamento orgânico de águas residuárias de suinocultura, superiores às aplicadas neste trabalho (164 a $607 \mathrm{~kg} \mathrm{ha}^{-1} \mathrm{~d}^{-1}$ de DBO), obtiveram concentrações de 2,99 a 3,27 e de 4,31 a 4,68 dag kg-1 de nitrogênio em SACs cultivados com taboa e capim tifton, respectivamente.

Assim como ocorreu em relação ao nitrogênio, a concentração de fósforo (Quadro 3) na parte aérea do lírio amarelo foi menor no material vegetal coletado no segundo corte que no primeiro. Não houve diferença significativa nas concentrações foliares de P com o aumento na taxa de carregamento orgânico, excetuando-se as obtidas nas plantas do SAC 3, que apresentou o menor valor.

Oliveira et al. (1999) observaram redução linear na concentração de P com a idade de rebrota do capim tifton 85 , estimando concentrações de 0,98

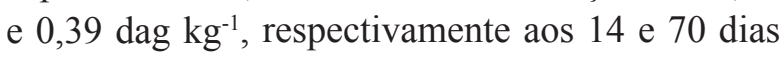
após a rebrota.

As concentrações de fósforo no material vegetal do primeiro corte foram semelhantes às obtidas por Brasil et al. (2007a) e Fia et al. (2011), ao cultivarem taboa em SACs para tratamento de esgoto doméstico $\left(0,28 \mathrm{dag} \mathrm{kg}^{-1}\right)$ e suinocultura $(0,25 \mathrm{dag}$ $\left.\mathrm{kg}^{-1}\right)$, respectivamente; e inferiores às obtidas por Matos et al. (2009), que obtiveram 0,44 dag $\mathrm{kg}^{-1}$ no cultivo da taboa nos SACs utilizados para tratar efluentes da suinocultura; Matos et al. (2008), que obtiveram a concentração média de 0,36 dag kg1 ao cultivarem capim tifton 85 em SACs para tratamento da água residuária de laticínios e Fia et al. (2011), que obtiveram concentrações médias de $0,90 \mathrm{dag} \mathrm{kg}^{-1}$, ao cultivarem capim tifton $85 \mathrm{em}$ SACs utilizados no tratamento da água residuária de suinocultura. No entanto, foram superiores às concentrações médias obtidas por Fia et al. (2010), que foram de 0,17 e $0,22 \mathrm{dag}_{\mathrm{kg}^{-1}}$ de P em SACs cultivados com azevém e aveia, respectivamente, no tratamento de águas residuárias do processamento dos frutos do cafeeiro. 
Torna-se importante ressaltar que as espécies vegetais cultivadas em SACs para o tratamento de esgoto doméstico devem ser eficientes na remoção de nutrientes do sistema, sobretudo de $\mathrm{N}$ e P, importantes fontes de poluição das águas; assim, pode-se considerar que o lírio amarelo é uma espécie apta a ser cultivada em SACs, principalmente em relação ao tratamento de esgoto doméstico, já que acumulou em seu tecido foliar concentrações de $\mathrm{N}$ e $\mathrm{P}$ semelhantes às acumuladas em forrageiras, mesmo recebendo taxas de carregamento orgânico bem menores que às referidas nos trabalhos citados anteriormente.

A concentração de $\mathrm{K}$ no material vegetal amostrado (Quadro 3) foi inferior às obtidas por Brasil et al. (2007a), que foi de 2,42 dag $\mathrm{kg}^{-1}$, por Matos et al. (2010), de 2,83 dag $\mathrm{kg}^{-1}$, quando se avaliaram o uso da taboa em SACs, respectivamente no tratamento de esgoto doméstico e efluentes da suinocultura. Foram inferiores, também, às obtidas por Fia et al. (2011), que foram de 2,71 e 2,05 dag $\mathrm{kg}^{-1}$, respectivamente em taboa e capim tifton, quando cultivados em SACs para o tratamento de águas residuárias da suinocultura, e por Fia et al. (2010), que obtiveram concentrações médias de 2,8 e 2,23 dag $\mathrm{kg}^{-1}$ em SACs cultivados com azevém e aveia, respectivamente, no tratamento de águas residuárias do processamento dos frutos do cafeeiro.

Observou-se que o teor de sódio (Quadro 3) presente no material vegetal coletado no segundo corte foi menor que no primeiro corte, com exceção do que foi encontrado nas plantas do SAC 2. Acredita-se que com a mineralização do material orgânico no sistema tenha disponibilizado, com o tempo, maior quantidade de íons no meio, o que fez diminuir a absorção de Na pelas plantas. No caso das plantas do SAC 2, o comportamento de maior acúmulo de sódio, pode ter sido um mecanismo de controle da toxicidade por ele provocada no meio, o que redundou em maior produtividade de massa seca das plantas.

As concentrações de $\mathrm{Na}$ nos tecidos foliares obtidas neste trabalho foram inferiores às encontradas por Brasil et al. (2007a), 0,80 dag $\mathrm{kg}^{-1}$ e Fia et al. (2011), 0,86 dag $\mathrm{kg}^{-1}$ quando cultivaram taboa em sistemas alagados artificiais para tratamento de esgoto doméstico e águas residuárias da suinocultura, respectivamente. No entanto, os valores obtidos neste trabalho foram superiores aos obtidos por Fia et al. (2011), 0,022 dag $\mathrm{kg}^{-1}$ e por Matos et al. (2008), 0,03 dag kg-1 de sódio nas folhas do capim tifton-85 cultivado em SACs tratando, respectivamente, água residuária de suinocultura e de laticínios.

Apesar dos cuidados exigidos, a espécie Hemerocallis flava apresenta vantagens em relação à taboa, quais sejam, beleza de suas flores, que auxiliam no paisagismo do ambiente e possibilidade da comercialização da citada espécie, gerando, portanto, benefício financeiro para a comunidade.

\section{CONCLUSÕES}

Com base nos resultados obtidos, pode-se concluir que:

- O desempenho agronômico e, em específico, a altura e a produtividade de massa seca da parte aérea das plantas em SACs devem ser avaliadas após o período de adaptação das plantas (cerca de 10 meses após o plantio);

- No cultivo de lírio amarelo em SACs utilizados no tratamento de esgoto doméstico, a Taxa de Aplicação Superficial recomendada deve estar próxima de $98 \mathrm{~kg} \mathrm{ha}^{-1} \mathrm{~d}^{-1}$ de DBO, tendo em vista que, nessas condições se obtém a maior produtividade de matéria seca e maior número de flores.

\section{REFERÊNCIAS BIBLIOGRÁFICAS}

APHA - American Public Health Association; AWWA - American Water Works Association; WEF - Water Environment Federation. Standard methods for the examination of water and wastewater, $21^{\text {th }}$. ed. Washington. D.C.: APHA/AWWA/WEF, 2005. $1268 \mathrm{p}$.

BELMONT, M.A.; METCALFE, C.D. Feasibility of using ornamental plants (Zantedeschia aethiopica) in subsurface flow treatment wetlands to remove nitrogen, chemical oxigen demand and nonylphenol ethoxylate surfactants - a laboratoryscale study. Ecological Engineering, Amsterdam, v.21, n.1, p.233-247, 2003. 
BRASIL, M.S.; MATOS, A.T. Avaliação de aspectos hidráulicos e hidrológicos de sistemas alagados construídos de fluxo subsuperficial. Engenharia Sanitária e Ambiental, Rio de Janeiro, v.13, n.3, p.323-328, 2008.

BRASIL, M.S.; MATOS, A.T.; FIA, R.; SILVA, N.C.L. Desempenho agronômico de vegetais cultivados em sistemas alagados utilizados no tratamento de águas residuárias da suinocultura. Engenharia na Agricultura, Viçosa, v.15, n.3, p.307-315, 2007a.

BRASIL, M.S; MATOS, A.T.; SILVA, C.M.; CECON, P.R.; SOARES, A.A. Modeling of pollution removal in contructed wetlands with horizontal subsurface flow. Agricultural Engineering Research, Agrartechnische Forschung, v.13, n.2, p.48-56, 2007b.

FIA, F.R.L; MATOS, A.T.; FIA, R.; LAMBERT, T.F.; MATOS, M.P. Remoção de nutrientes por Typha latifolia e Cynodon spp. cultivadas em sistemas alagados construídos. Ambi-água, Taubaté, v.6, n.1, p.77-89, 2011.

FIA, R.; MATOS, A.T.; FIA, F.R.L.; MATOS, M.P.; LAMBERT, T.F.; NASCIMENTO, F.S. Desempenho de forrageiras em sistemas alagados de tratamento de águas residuárias do processamento do café. Revista Brasileira de Engenharia Agrícola e Ambiental, Campina Grande, v.14, n.8, p.842-847, 2010.

FREITAS, W.S. Desempenhode sistemas alagados construídos, cultivados com diferentes espécies vegetais, no tratamento de águas residuárias da suinocultura. 2006. 159f. Tese (Doutorado em Engenharia Agrícola) - Universidade Federal de Viçosa, Viçosa. 2006

HUSSAR, G.J. Avaliação do desempenho de leitos cultivados no tratamento de águas residuárias de suinocultura. 2001. 118f. Dissertação (Mestrado em Engenharia Agrícola) - Universidade Estadual de Campinas, Campinas. 2001.

KADLEC, R.H.; WALACE, S.D. Treatment wetlands. 2. Ed., New York, Taylor \& Francis Group, 2009. 1016p.
KIEHL, E.J. Fertilizantes orgânicos. 1. Ed., Piracicaba, Agronômica Ceres, 1985. 492p.

KONNERUP, D.; KOOTTATEP, T.; BRIX, H. Treatment of domestic wastewater in tropical, subsurface flow constructed wetlands planted with Canna and Heliconia. Ecological Engineering, Amsterdam, v.35, n.2, p.248-257, 2009.

MATOS, A.T.; ABRAHÃO, S.S.; PEREIRA, O.G. Desempenho agronômico de capim tifton 85 (cynodon spp) cultivado em sistemas alagados construídos utilizados no tratamento de água residuária de laticínios. Ambi-Água, Taubaté, v.3, n.1, p.3-53, 2008.

MATOS, A.T.; FREITAS, W.S.; LO MONACO, P.A.V. Capacidade extratora de diferentes espécies vegetais cultivadas em sistemas alagados utilizados no tratamento de águas residuárias da suinocultura. Ambi-Água, Taubaté, v.4, n.2, p.119-132, 2009.

MATOS, A.T.; FREITAS, W.S.; LO MONACO, P.A.V. Eficiência de sistemas alagados construídos na remoção de poluentes de águas residuárias da suinocultura. Ambi-Água, Taubaté, v.5, n.2, p.3145, 2010 .

OLIVEIRA, M.A. Morfogênese, análise de crescimento e valor nutritivo do capim tifton-85 (Cydonon spp.) em diferentes idades de rebrota. 1999. 94p. Dissertação (Mestrado). Universidade Federal de Viçosa, Viçosa. 1999.

TUNÇSIPER, B.; AYAZ, S.Ç.; AKÇA, L. Performances analysis and modeling of an experimental constructed wetlands. Proceedings... 6th INTERNATIONAL CONFERENCE ON WASTE STABILISATION PONDS and 9th INTERNATIONAL CONFERENCE ON WETLAND SYSTEMS FOR WATER POLLUTION CONTROL. Avignon, France, IWA/Astee, OC-40, CD-ROM. 26th of Sept. - 1st of October 2004.

WANG, R.; KORBOULEWSKY, N.; PRUDENT, P.; BALDY, V.; BONIN, G. Can vertical-flow wetland sustems treat high concentrated sludge from a food industry? A mesocosm experiment testing three plant species. Ecological Engineering, Amsterdam, v.35, n.2, p.230-237, 2009. 
ZANELLA, L. Plantas ornamentais no póstratamento de efluentes sanitários: wetlandsconstruídos utilizando brita e bambu como meio suporte. 2008. 189f. Tese (Doutorado em Engenharia Civil). Universidade Estadual de Campinas, Campinas. 2008.

ZURITA, F.; BELMONT, M.A.; ANDA, J.D.; MARTINEZ, J.C. Stress detection by laser-induced fluorescence in Zantedeschia aethiopica planted in subsurface-flow treatment wetlands. Ecological Engineering, Amsterdam, v.33, n.2, p.110-118, 2008.

ZURITA, F.; ANDA, J.D.; BELMONT, M.A. Treatment of domestic wastewater and production of commercial flowers in vertical and horizontal subsurface-flow constructed wetlands. Ecological Engineering, Amsterdam, v.35, n.5, p.861-869, 2009. 